\title{
Storage Media for Avulsed Tooth-A Review
}

\author{
Dr. Shakir Hussain Rather ${ }^{1 *}$, Dr. Niveda ${ }^{2}$, Dr. Salman bhai Karbhari ${ }^{2}$
}

${ }^{1}$ MDS Department of Pedodontics and Preventive Dentistry

${ }^{2}$ BDS, Priyadarshini Dental College \& Hospital, Chennai, India

DOI: $10.36348 /$ sjbr.2020.v05i11.008

| Received: 09.11.2020 | Accepted: 21.11.2020 | Published: 23.11.2020

*Corresponding author: Dr. Shakir Hussain Rather

\section{Abstract}

Dental avulsion is the complete dislodgement of a tooth from its alveolar socket caused by certain traumatic injuries. The ideal treatment is to reimplant the tooth in its respective socket. The success of reimplanting an avulsed tooth depends on the viability of PDL cells, the available peridontium to support the tooth and the storage media where the avulsed tooth is temporarily preserved. The proper use of storage media helps in maintaining the viability of the PDL cells whereas the incorrect use of the storage media may lead to necrosis of PDL cells or root resorption. This literary review discusses the significant importance of storage media and its biological properties in reimplanting an avulsed tooth.

Keywords: Avulsion, storage media, PDL cells, Replantation.

Copyright (C) 2020 The Author(s): This is an open-access article distributed under the terms of the Creative Commons Attribution 4.0 International License (CC BY-NC 4.0) which permits unrestricted use, distribution, and reproduction in any medium for non-commercial use provided the original author and source are credited.

\section{INTRODUCTION}

Dental avulsion is the tramautic separation of the tooth from its alveolus and is a common emergency situation in dental practice. Avulsion of permanent teeth is the most serious of all types of traumatic tooth injuries because the complete dislodgement of the tooth from its socket causes severe damage to the supporting tissues and vascular and nerve structures [1]. Reported incidence of dental avulsion is $1-11 \%$ of all dental injuries to the permanent dentition, with the maxillary central incisor being the most frequently involved tooth. The age group of 7-10 years appears to be most affected. The treatment is to reimplant the avulsed tooth immediately but this is not possible in most cases considering other existing life threatening injuries, patient's emotional condition and simply lack of knowledge about the reimplanting procedures. The lack of first aid knowledge about the avulsion among the public and health care centres delays immediate replantation and limits the prognosis of the avulsed tooth [2, 3]. For a good prognosis the extra oral dry time to which the avulsed tooth is exposed and the clonicity and progenicity of the viable PDL cells has to be maintained. This can be made feasible using a suitable storage medium for preserving the avulsed tooth that Maintains viability of periodontal fibres.

\section{NATURAL STORAGE MEDIA TAP WATER}

Use of tap water to store avulsed tooth is not recommended as it is not compatible with PDL cells because of its hypotonic osmolarity which causes cell lysis, and is reported to cause replacement resorption in avulsed teeth when they are place in it [2]. Tap water or normal water is considered as least used storage media since its efficacy is very poor.

\section{SALIVA}

It is of short period of time having osmolality $60-70 \mathrm{mOsm} / \mathrm{kg}$ (much less than physiologic). So if storing duration goes for 2 to $3 \mathrm{hrs}$ it may causes swelling and membrane damage of PDL cells [4]. Though Saliva is a readily available it can only be used as an interim storage medium not more than 30 minutes.

\section{MILK}

Milk is one of the sort after traditional storage media as it is cost effective. With a $\mathrm{pH}$ of 6.5-7.2 and the presence of essential nutrients important for maintaining the viability of PDL cells [5, 6], milk can be considered as acceptable storage medium in most situations, increasing the life of the PDL cells on the root surface, pasteruisation decreases the number of bacteria and its products. Several investigators like Blomlof L, Otteskog P 1980 [7], Marino et al., 2000 [8], Lekic et al., 1998 [9] compared milk with several other storage media and found that milk was superior to the others in maintaining the viability but not as good as HBSS [4]. Sour milk should not be used as it is harmful [11]. Refrigerated milk helps in maintaining the viability of PDL cells compared to milk in room 
temperature. Inspire all the favorable factors of milk as storage media it has not been proven to revive the degenerated cells [2].

\section{EGG WHITE}

Egg white is another easily available storage media. Presence of high protein content, vitamins and being uncontaminated by microbes makes it a good choice. With a $\mathrm{pH}$ of 6.6 and osmolality 251-258 it has a better incidence of repair than milk for up to 6-10 h $[2,10]$. However there was no significant difference when compared with HBSS [11].

\section{EMDOGAIN}

Emdogain or EMD is a commercialized product which contains from enamel matrix protein. It is believed to induce acellular cementum formation favoring periodontal regeneration. However, no firm conclusion regarding the efficacy of EMD application on healing of replanted and autotransplanted permanent teeth can be drawn because of a lack of randomised controlled trials and clinical controlled trials [4].

\section{PROSPOLIS}

Propolis is a natural substance produced by honeybees with remarkable antioxidant, antiinflammatory and antimicrobial properties [1]. Main composition propolis includes a) Resin (rich in flavonoids) $-45-55 \%$ b) Waxes and Fatty acids -23$35 \%$ c) Essential oils $-10 \%$ d) Pollen proteins $-5 \%$ e) Other organic compounds and minerals [4]. Recent studies have shown $10 \%$ of propolis to be an effective storage media when compared with milk, HBSS, tap water and DMEM [2]. Though propolis has a good efficacy as a storage media its lack of availability it is rarely used.

\section{COCONUT WATER}

Coconut water [12] is purely natural and rich in nutrients. It has a $\mathrm{pH}$ of 4.1 and osmolality of 288 $\mathrm{msom} / \mathrm{Kg}$. When compared with other media like HBSS, propolis and milk, it was found that coconut water was the most effective in maintaining viability of PDL cells ${ }^{2}$. But the acidic $\mathrm{pH}$ appeared to be more deleterious to cell metabolism and neutralizing $\mathrm{pH}$ of coconut water is difficult [3]. Hence further investigation and research is required to accept it as a storage media.

\section{GREEN TEA EXTRACT (GTE)}

Green tea is rich in polyphenol Epigallocatechin gallate known for its antioxidant and anti inflammatory properties.The efficacy of GTE maintaining the viability of PDL [13] cells was similar to that of HBSS and higher than that if milk and was concluded to be a suitable storage medium $[3,4]$.

\section{MORUS RUBRA}

Morus rubra also known as red mulberry fruit from the family moraceae and is rich in flavonoids, alkaloids and polysaccharides. In a study Morusrubra juice at $4 \%$ concentration was found to be superior to HBSS for maintaining PDL cell viability forupto 12 hours [14, 4]. More research on Morus rubra is needed for its use as an approved storage medium.

\section{SALVIA OFFICNALIS EXTRACT}

Salvia Officinalis is a plant from the family Lamiaceae. It has been used since ancient times as an astringent and antiseptic. The antioxidants present in the extract help to prevent root resorption by inhibiting the effect of osteoclastic cells. Studies have shown that Salvia extract at $2.5 \%$ helps maintain PDL cells viability over longer periods of time $(3,6,12$ or 24 hours) when compared with HBSS, phosphate buffered saline and tap water [15]. This extract has been proposed as a storage medium for avulsed teeth because of the anti-oxidants effects caused due to the presence of its phenolic components like rosmarinic acid, camosic acid, salvianolic acid and derivatives [2].

\section{ARTIFICIAL STORAGE MEDIA SALINE SOLUTION}

Saline has a pH of 7 and osmolality of 280 msom/kg which are biocompatible to PDL cells (27). The lack of nutrients such as potassium, magnesium etc in saline is a setback as these nutrients are required for the metabolic activity of PDL cells. It is acceptable to place avulsed teeth in this storage medium but for not more than 10 minutes. In a study by Raghoebar the tooth stored in gauze soaked in sterile saline, has been evaluated to show good results in tooth reimplantation $[2,4]$.

\section{Hanks Balanced Salt Solution (HBSS)}

Hanks Balanced Salt Solution was introduced by John. H. Blank and consists of inorganic salts supplemented with glucose. It is considered as a standard solution in biomedical field and is widely used to preserve tissue cultures. HBSS has a $\mathrm{pH}$ of 7.2 and osmolality of $320 \mathrm{msOm} / \mathrm{kg}^{3}$. It is composed of $8 \mathrm{~g} / \mathrm{L}$ sodium chloride; $0.4 \mathrm{~g} / \mathrm{L}$ of D-glucose; $0.4 \mathrm{~g} / \mathrm{L}$ potassium chloride; $0.35 \mathrm{gl}$ sodium bicarbonate; $0.09 \mathrm{~g} / \mathrm{L}$ sodium phosphate; $0.14 \mathrm{~g} / \mathrm{L}$ potassium phosphate; $0.14 \mathrm{~g} / \mathrm{L}$ calcium chloride $; 0.1 \mathrm{~g} / \mathrm{L}$ magnesium chloride and $0.1 \mathrm{~g} / \mathrm{L}$ magnesium phosphate [2]. It is non-toxic, biocompatible and does not require refrigeration, has a long shelf life of 2 years [6]. Ashkenazi et al showed the highest mitogenicity of PDL cells after 8 and 24 hours of storage was found in HBSS. American Association of Endodontists recommends the use of HBSS as the storage medium of choice for treatment of avulsed tooth because of its ability to provide long term preservation of PDL cell viability [10]. It has been recommended to place avulsed teeth in HBSS for 30 minutes before reimplantation in order to replenish the PDL cells, even if the avulsed teeth have been stored in an appropriate storage medium [17]. HBSS is considered as a superior storage media to which other storage mediums are compared. 


\section{GATORADE}

It is a non carbonated sports drink used by athletes to replenish lost electrolytes. Gatorade has a pH of 2.91 and osmolality of $407 \mathrm{msOm} / \mathrm{kg}$. It contains sodium, calcium, potassium and glucose required for cell metabolism [3, 4]. Though it is readily available at sports events where injuries tend to occur it is still not recommended as a long-term storage medium because of its high osmolarity. Studies suggest that Gatorade is a better storage media compared to tap water.

\section{RICETRAL}

Ricetral is a commercially available oral rehydration solution consisting of vital salts and glucose required to maintain cell metabolism. Studies suggest ricetral had a high PDL cell vitality similar to HBSS [11].

\section{VIASPAN}

ViaSpan is a cold storage solution which was designed to use in organ transplantation. It has a $\mathrm{pH}$ of 7.4 , osmolality of $320 \mathrm{msOm} / \mathrm{kg}$ and is a potent antioxidant $[3,7]$. A study by Ashkenazi et al., showed that the clonogenic capacity of stored cells kept in ViaSpan for 8 hours was high and comparable to HBSS and superior to Milk [4, 8]. The major drawback of viaspan is the short expiration, the need to be refrigerated and high cost.

\section{EAGLE'S MINIMAL ESSENTIAL MEDIUM}

Eagle's Minimal Essential Medium contains 4 $\mathrm{ml}$ of L-Glutamine; $105 \mathrm{IU} / \mathrm{L}$ of Penicillin; $100 \mu \mathrm{g} / \mathrm{mL}$ of Streptomycin, $10 \mu \mathrm{g} / \mathrm{mL}$ of Nystatin and calf serum $(10 \% \mathrm{v} / \mathrm{v})$. Ashkenazi et al., 's study showed that this medium had relatively high viability, mitogenic and clonogenic capacity up to 8 hours of storage at $4^{\circ} \mathrm{C}[12$, $13,4]$. It was less effective than milk and HBSS when stored upto $24 \mathrm{hrs}$. Research has demonstrated that the use of special cell culture medium (SCCM), which has been formulated especially to be used as a storage medium for avulsed teeth, is better at maintaining PDL cell viability than HBSS for time period of longer than 24 hours. Another variation of Eagle's Modified Essential Medium (EMEM) is Dubelco's modified Eagle's Medium (DMEM) which contains a greater concentration of vitamins and amino acids as well as glucose compared to the EMEM ${ }^{2}$. Since it is more effective in culture medium EMEM is not readily available.

\section{CASEIN PHOSPHOPEPTIDE}

Casein Phosphopeptide is a derivative of casein which is composed of phosphoproteins. In a study which investigated the use of different concentration of commercial CPP-amorphous calcium phosphate as storage media by observing morphological changes in fibroblast cells, it was found that cell apoptosis did not occur when very dilute concentrations of CPP-ACP [10-12] was used as storage medium [2, 8,
9]. However further research is required to determine the ideal concentration of this storage media.

\section{CUSTODIAL}

Custodial or Histidine-tryptophanketoglutarate (HTK solution) is used as a preservation solution for organ transplantation. It contains sodium, potassium, calcium, Mannitol and Histidine. The osmolarity of HTK is $310 \mathrm{mOsm} / \mathrm{L}$. A recent study by Tae Jun Oh et al suggested that 50\% HTK solution containing cell culture medium represents a suitable storage medium for avulsed teeth (46).

\section{ASCORBIC ACID}

Studies have shown that the use of Ascorbic Acid had an effect on osteoblastic differentiation of PDL cells. Ishikawa et al., [13] suggested that ascorbic acid increased the Alkaline Phosphatase activity which is important for binding of PDL cells to type I collagen via 2 beta 1 integrin, whose expression is again increased by ascorbic acid. This observation suggests that Ascorbic Acid can be used as a potential storage media.

\section{READY MADE KITS TOOTH RESCUE BOX}

Tooth rescue box is commercially marketed as Dentosafe in Germany and EMT tooth saver in USA. It contains a special cell culture medium (SCCM) which is a combination of amino acids vitamins and glucose [2]. It has shown the ability to maintain the vitality of PDL for $48 \mathrm{hrs}$ at room temperature [14]. Study by Pohl et al showed that avulsed tooth placed in dentosafe promotes functional healing [16]. It is recommended to have Dentosafe in all first kits during sports events and other places where tooth avulsion dur to injury is prone to happen.

\section{SAVE -A-TOOTH}

"Save-A-Tooth" emergency tooth preserving system a commercially available product by Phoenix Lazarus contains HBSS solution in a 6 part system to preserve the PDL cells of avulsed tooth. Unfortunately both the ready made tooth rescue kits are still not available in India.

\section{OTHER RECENT RESEARCH IN STORAGE MEDIA \\ Growth Factors}

Polypeptide growth factors have shown to promote PDL regeneration. Lynch et al 35 demonstrated that short-term application of a combination of platelet-derived growth factor- (PDGF-) and insulin-like growth factor (IGF) can enhance the formation of the periodontal attachment apparatus healing [12]. It has been observed that fibroblasts exposed to growth factors increased the mitogenic capacity of the cells. 


\section{L -Dopa}

Levodopa belongs to the class of medications called cental nervous system agents. L-Dopa developed by Sigma chemical, Perth, Australia is a drug with possible mitogenic effect. It stimulates the secretion of growth hormone from the pituitary gland which aids in the healing process. Partovi et al., observed the effect of levodopa on human PDL fibroblasts and stated that it can also have a local effect on growth of cells and can act as preserving medium for avulsed teeth $[3,4]$.

\section{Cryoprotective agents}

Cryoprotective agents are generally used to protect biological tissue from freezing damage. Schwartz and Andreasen [15] studied the effects of the cryopreserving agents (cryoprotectives) $5 \%$ and $10 \%$ dimethyl sulphoxide (DSMO) and 10\% glycerol, on PDL. They observed that the use of different cryoprotectives, combined with controlled freezing rates to $-196^{\circ} \mathrm{C}$, can preserve the PDL of the replanted teeth to a greater or lesser extent [12].

\section{Cling Film}

Cling Film is made out of variety of plastics and the most common material used is polyvinyl chloride. It is thin and used to seal any items to keep them fresh. According to Anja Zeissler et al., cling film storage medium shows probability of cell growth at the withdrawal time of 2 hours shows $86 \%$ and thus is very high compared to tooth rescue box [4]. It is suggested that cling film can be used as a alternative storage media for upto 6 hours.

\section{CONCLUSION}

Inspite of several studies and investigations on different products still a perfect storage media for an avulsed tooth that meets the ideal characteristics hasn't been confirmed. The major drawback of many storage media discussed here is its lack of availability and high cost. Based on investigations so far, apart from solutions designed specifically for storage and culture purposes. Milk is considered to be an easily available storage media out of all its use is recommended by the International Association of Dental Traumatology and the American Academy of Pediatric Dentistry as a temporary storage medium for avulsed tooth. Hence public awareness of using storage media is required to save avulsed which would help in better prognosis.

\section{REFRENCES}

1. Poi, W. R., Sonoda, C. K., Martins, C. M., Melo, M. E., Pellizzer, E. P., Mendonça, M. R. D., \& Panzarini, S. R. (2013). Storage media for avulsed teeth: a literature review. Brazilian Dental Journal, 24(5), 437-445.

2. Adnan, S., \& Farhan, R. K. (2014). Storage Media for Avulsed Teeth: A Literature Review. JPDA; 23(2):54-60.
3. Poornima, P., Kotari, S., Sasalawad, S. S., Nagaveni, N. B., Roshan, N. M., \& Subba Reddy, V. V. (2015). Save cells before tooth replantation: A review. Int $\mathbf{J}$ Contemp Dent Med Rev, 2015, 1-7.

4. Nabi, S., Kavikumar, V., \& Tahir, A. (2018). Storage Media For Avulsed Tooth-A Review. European Journal of Biomedical, 5(9), 130-133.

5. Hwang, J. Y., Choi, S. C., Park, J. H., \& Kang, S. W. (2011). The use of green tea extract as a storage medium for the avulsed tooth. Journal of Endodontics, 37(7), 962-967.

6. Malhotra, N. (2011). Current developments in interim transport (storage) media in dentistry: an update. British dental journal, 211(1), 29-33.

7. Blomlöf, L., \& Otteskog, P. (1980). Viability of human periodontal ligament cells after storage in milk or saliva. European Journal of Oral Sciences, 88(5), 436-440.

8. Marino, T. G., West, L. A., Liewehr, F. R., Mailhot, J. M., Buxton, T. B., Runner, R. R., \& McPherson III, J. C. (2000). Determination of periodontal ligament cell viability in long shelf-life milk. Journal of Endodontics, 26(12), 699-702.

9. Lekic, P. C., Kenny, D. J., \& Barrett, E. J. (1998). The influence of storage conditions on the clonogenic capacity of periodontal ligament cells: implications for tooth replantation. International endodontic journal, 31(2), 137-140.

10. Poi, W. R., Sonoda, C. K., Martins, C. M., Melo, M. E., Pellizzer, E. P., Mendonça, M. R. D., \& Panzarini, S. R. (2013). Storage media for avulsed teeth: a literature review. Brazilian Dental Journal, 24(5), 437-445.

11. Rajendran, P., Varghese, N. O., Varughese, J. M., \& Murugaian, E. (2011). Evaluation, using extracted human teeth, of Ricetral as a storage medium for avulsions-an in vitro study. Dental Traumatology, 27(3), 217-220.

12. Bazmi, B. A., Singh, A. K., Kar, S., \& Mubtasum, H. (2013). Storage media for avulsed tooth-a review. Indian Journal of Multidisciplinary Dentistry, 3(3):741-749.

13. Ishikawa, S., Iwasaki, K., Komaki, M., \& Ishikawa, I. (2004). Role of ascorbic acid in periodontal ligament cell differentiation. Journal of periodontology, 75(5), 709-716.

14. Pohl, Y., Tekin, U., Boll, M., Filippi, A., \& Kirschner, H. (1999). Investigations on a cell culture medium for storage and transportation of avulsed teeth. Australian Endodontic Journal, 25(2), 70-75.

15. Andreasen, J. O., Borum, M. K., Jacobsen, H. L., \& Andreasen, F. M. (1995). Replantation of 400 avulsed permanent incisors. 1. Diagnosis of healing complications. Dental Traumatology, 11(2), 51-58.

16. Pohl, Y., Filippi, A., \& Kirschner, H. (2005). Results after replantation of avulsed permanent teeth. II. Periodontal healing and the role of physiologic storage and antiresorptive- regenerative therapy. Dental Traumatology, 21(2), 93-101.

17. Buttke, T. M., \& Trope, M. (2003). Effect of catalase supplementation in storage media for avulsed teeth. Dental Traumatology, 19(2), 103-108. 